\title{
The effect of the EMU on short and long-run stock market dynamics: New evidence on financial integration
}

\author{
Juan Angel Lafuente * \\ Department of Finance and Accounting \\ Universitat Jaume I
}

\author{
Javier Ordóñez \\ Department of Economics \\ Universitat Jaume I
}

January 2007

\begin{abstract}
This paper deals with the time evolution of stock market integration around the introduction of the euro. In particular we test whether the degree of integration between the main eurozone countries increased after European monetary union. The contribution of the paper to the extant literature is twofold: a) first, we take into account the potential long-run equilibrium relationship between stock indices allowing for structural changes in the cointegration space that might capture the effect of the introduction of the euro, and b)we formally test the existence of greater financial integration after European monetary union across the main member countries and between these members and the UK. Empirical evidence reveal the existence of long-run equilibrium relationships between European stock markets even before the introduction of the euro. Our empirical findings suggest that financial integration is not the direct consequence of the removal of exchange rate risk due to currency unification. Rather, it arises as a result of macroeconomic convergence. This aspect is corroborated by the nature of the principal component structure of estimated conditional correlations.
\end{abstract}

Classification J.E.L.: C32, E44, G15.

Key words: cointegration, dynamic financial integration, stock markets, European Monetary Union.

\footnotetext{
${ }^{*}$ Corresponding author: Department of Finance and Accounting, Universitat Jaume I. Campus de Riu Sec. E-12080 Castellón (Spain). e-mail: jmonfort@eco.uji.es. Financial support from the Spanish Ministry of Education through grant BEC2003-03965 is gratefully acknowledged.The usual disclaimer applies.
} 


\section{Introduction}

The increasing globalization of the world economy has led to a significant spread in the scope of financial transactions among countries. Not only might economic integration influence the degree of capital market integration across countries over time, but it may also contribute to international financial stability. The academic literature on comovements among international stock markets generally find that globalization is attached to increasing financial integration. For example, Chelley-Steeley (2005), shows that the degree of segmentation experienced by certain eastern European markets declined significantly over the period 1994-1999; Ayuso and Blanco (2000) provide empirical evidence for European countries of a significant increase during the nineties, not only in the weight of foreign assets in agents' portfolios, but also in the correlation between stock indices, while Fujii (2005) reports that linkages between the Asian and Latin American geographical areas were strengthened around the time of major financial crises during the nineties, i.e. the 1994-95 Mexican and the 1997-98 Asian crises. Also, Berben and Jansen (2005) find that correlations among the German, UK, and US stock markets more than doubled between 1980 and 2000 .

The study of the nature of financial integration is important because of its real and financial effects. Financial integration tends not only to increase international correlations in both consumption and GDP fluctuations (see Imbs, 2006), but also to affect the relationship between output growth and volatility (see Kose et al., 2006, who provide empirical evidence to show that although the negative relationship between volatility and growth survived into the 1990s, it tends to be weakened by financial integration). In addition, time varyingmarket integration in the world market is an important determinant of the expected returns and the cost of capital in emerging markets, basically due to the diminishing diversification benefits derived from trading in developed stock markets. Consistent with this idea, de Jong and de Roon (2005) who analyze 30 emerging markets in Asia, the Far East, Europe, the Mideast and Africa, find that a decrease in segmentation leads to lower expected returns even when it is accompanied by an increase in beta.

One of the most important event concerning financial economic integration is the recent past experience of introducing the euro, which has undoubtedly influence the nature of the correlations between the stock markets of the European monetary union member countries (see, for example, Kim et al., 2005, 2006). Given that capital flows across international financial markets follow return differentials, the existence of a common monetary policy between the member countries of the monetary union should leads to a greater homogeneous investment opportunities across these economies, and then reducing the potential benefits of international diversification.

This paper deals with dynamic stock market integration encouraged by the 
European monetary union for the main member countries (Germany, France, Italy and Spain) and the UK. While the recent papers of Kim et al. (2005, 2006) focus on the dynamic stock market integration between either a specific country and the rest of Europe or different financial assets (stocks and bonds) this paper examines with dynamic interactions within the monetary union. Although it has been well documented that economic integration tends to reduce the benefits of international diversification (trends in stock prices become more similar) the potential existence of cointegration relationships has not been taken into account to estimate time-varying correlations. Not considering this potential feature of the data could lead to model misspecification. This paper contributes to the literature by analyzing short and long-run financial integration. First we account for potential economic long-run equilibrium relationships between stock market indices to estimate time-varying correlations of stock returns. And secondly, we use non-parametric techniques to test whether the distribution of correlations across countries has changed over time. Empirical findings can be summarized as follows: a) the introduction of the euro has undoubtedly stabilized the process of financial integration across the main member countries of the EMU; b) long-run equilibrium relationships existed between European stock markets even before the introduction of the euro; c) however, the exogeneity of the UK stock index in the cointegration space show that long-run financial integration only appears among the eurozone member countries.

The rest of the paper is organized as follows. Section II discusses the data used. Section III describes the cointegration analysis. Section IV present the bivariate GARCH methodology to estimate time-varying correlations and section V reports empirical results. Finally, Section VI summarizes and provides concluding remarks.

\section{Data}

In this section we discuss the data used and some preliminary statistical properties of stock index returns. The data set comprises daily closing stock market indices from the main eurozone members (Germany, France, Spain and Italy), as well as the UK, which is the nearest non-eurozone country with the highest industrialization ${ }^{1}$. The sample period analyzed is from 21 April 1993 to 30 December 2004. Daily closing stock indices were taken from Bloomberg ${ }^{2}$. For each index, we compute the return as the log first differences between closing

\footnotetext{
${ }^{1}$ Despite the existence of "home bias", that is, the fact that investors across the world have small proportions of their assets allocated to foreign markets, Portes and Rey (2005) find that the most important determinant of global equity transactions between two countries is geographical proximity.

${ }^{2}$ The authors wish to thank Emilio Palomar for providing us with the data used.
} 
prices on trading day $t$-1 and $t$. From perspective of a policy maker concerned with financial integration, stock prices should closely reflect price discovery as it takes place in real financial markets. Consequently, we do not adjust stock returns of exchange rate fluctuations and dividend payments.

Table 1 reports some descriptive statistics. The daily close to close sample mean is negligible, as expected from a systematically long and short trading strategy on consecutive trading days. On an annual basis, the average return is about 18\% for Germany, $13 \%$ for both France and the UK and $20 \%$ for both Spain and Italy. Considering the standard deviation as a rough measure of volatility for the overall sample the highest volatility is for the Italian stock market while the lowest corresponds to the UK stock market. Moreover, stock return distributions have excess of kurtosis and are slightly skewed. Both characteristics are generally associated with conditional heteroskedasticity. To assess the existence of ARCH effects in stock returns, we perform Engle's Lagrange multiplier test. Empirical values of the test systematically reject the null, pointing towards a parametrization for the second order moments of stock market returns using a particular specification of the GARCH family of models.

\section{Identification of the long-run structure}

The empirical analysis of cointegration is based on the $\operatorname{VAR}(5)$ model with a constant restricted to lie in the cointegration space:

$$
\Delta x_{t}=\Gamma \Delta x_{t-1}+\alpha \tilde{\beta}^{\prime} \tilde{x}_{t-1}+\Phi D p_{t}+\varepsilon_{t}
$$

with:

$$
\tilde{\beta}^{\prime}=[\beta, \gamma, \delta] \text { and } \tilde{x}_{t-1}=\left[\begin{array}{c}
x_{t-1} \\
1 \\
D S_{t}
\end{array}\right]
$$

where $\tilde{\beta}^{\prime} \tilde{x}_{t-1}$ is a $r \times 1$ vector of stationary cointegration relation, $x_{t}$ is a $p \times 1$ vector of stock market indices of Germany, France, Spain, Italy and the UK (thus, $\mathrm{p}=5$ ), $\gamma$ corresponds to the restricted constant and $\delta$ stands for a mean shift in $\beta^{\prime} x_{t-1}$ as a result of a mean shift in the variables that do not cancel in the cointegrated relations. This mean shift is captured by a dummy, called $D S_{t}$ in $\tilde{x}_{t-1}$, which is zero until 1999 and one otherwise. This dummy aims to capture the introduction of the euro and the implementation of the common monetary policy. $D p_{t}$ stand for a permanent impulse dummy and corresponds to the first difference of $D s_{t}$. 
The baseline model was carefully checked for signs of misspecification using a variety of diagnostic tests, according to which, the model appears to describe the data reasonably well. There are no deviations from the basic assumptions of residual independence, although a certain degree of heteroscedasticity and non-normality were detected. According to Gonzalo (1994), even under these conditions, the estimation of the cointegration space by the maximum likelihood procedure proposed by Johansen (1988) is efficient. The conditional variance is subject to further modelling below using a GARCH approach.

The choice of the cointegration rank is based on the Bartlett corrected trace test, the roots of the characteristic polynomial and the t-statistic of the adjustment coefficients. All this information is shown in Table 2. The 5\% critical values for the trace test were simulated to account for the shift dummy restricted to the cointegration space. According to the trace test in table 2, we might accept $r=2$, although $r=3$ is also a plausible result. The roots of the characteristic polynomial of the VAR might also provide useful information about the rank. Thus, if a nonstationary vector is wrongly included in the cointegration space, the largest unrestricted characteristic root will be close to the unit circle. In our case, the difference between roots for different choice of $r$ is fairly small, and thus they are not very informative. This could be due to the existence of small $\mathrm{I}(2)$ components in the data. The middle panel in Table 2 presents the t-values for the adjustment coefficients. Only the FTSE-100 significantly adjusts to the third cointegration relation, which suggests that the choice of $r=2$ would involve no important loss of information.

Finally, as an additional check for the choice of the rank, Table 3 present the time series properties of long-run exclusion. This test might help to decide whether a variable improves the specification of the cointegration space. The choice of $r=3$ when compared with $r=2$ alters the statistical properties of the model: with the first choice, the CAC index is long-run excludable, although borderline. Hence, this index would not add significant information to the long-run analysis. However, there is no clear reason why this should be the case, and thus the choice $r=3$ might be inappropriate. Moreover, the presence of multicollinearity between variables can lead to acceptance of longrun exclusion, even though the variable is significant in the long-run relations. Given this possibility, we decided to keep the CAC index in the model and set $r=2$.

Table 3 also reports the test statistics for stationarity and weak exogeneity. These tests are also presented for $r=2$ and the two plausible alternatives $r=1$ and $r=3$. None of the stock indices is stationary. This result is independent of the choice of $r$. The weak exogeneity tests suggest that, for $r=2$ and $r=3$, both the CAC and FTSE-100 indices are weakly exogenous. If this were the case, shocks to both indices would drive the system in the sense that the other indices would adjust to CAC and FTSE-100 but the latter would not adjust to the remaining variables. These results are subject to further formal testing 
below.

The long-run identified structure is accepted with a p-value of 0.39. The first cointegration vector corresponds to:

$$
e c m 1_{t}=C A C 40_{t}-\underset{[-5.02]}{0.71} D A X_{t}-\underset{[-7.97]}{0.91} M I B T E L_{t}+\underset{[5.20]}{0.80} F T S E 100_{t}
$$

whereas the second one is given by:

$$
e c m 2_{t}=D A X_{t}+\underset{[3.85]}{0.65} \operatorname{IBEX} 35_{t}-\underset{[-8.76]}{2.01} \operatorname{FTSE} 100_{t}-\underset{[-2.93]}{0.10} D S_{\text {euro }}+\underset{[5.14]}{3.74}
$$

Both cointegration vectors are plotted in Figure 1. These graphics clearly suggest that the above relations are stationary.

The first cointegration vector links the whole set of analyzed stock indices with the sole exception of the IBEX-35. This means that the CAC-40, DAX, MIBTEL and FTSE-100 indices cannot move independently from each other, at least in the long-run. Thus, for example, if either DAX or MIBTEL goes up, CAC-40 also tends to increase, whereas CAC-40 returns are inversely related to those of FTSE-100. This result therefore reveals significant market interrelationships, furthermore, the existence of a long-run equilibrium across this set of stock indices implies some degree of market predictability, since deviations away from equilibrium are expected to be corrected.

The second cointegration vector can be interpreted as a long-run relation for the Spanish index, IBEX-35. It should be noted that while the long-run relationships linking the CAC-40, DAX, MIBTEL and FTSE-100 indices are not significatively affected by the introduction of the EMU, this is not the case for the IBEX-35. In order to find an equilibrium relationship linking the IBEX35 and (some of) the other indices, we need to include the dummy $D S_{\text {euro }}$ to capture the introduction of the euro, otherwise, cointegration can not be found. This result is interesting as it indicates that market interrelationships were already occurred before EMU creation for some, but not all, indices. The shift dummy in the equilibrium mean for the second cointegration vector suggests that the level of the returns for the IBEX-35 increased after the introduction of the EMU.

Parameter constancy of the cointegration space is checked using the recursive test procedures in Hansen and Johansen (1999). According to these tests the cointegration space is reasonably stable.

Next we tested the hypothesis that some of our indices might be weakly exogenous. This hypothesis is jointly tested with the identified long-run structure. The joint hypothesis is only accepted for FTSE-100, a non EMU member, with a p-value of 0.28 . This finding reveals that the long run dynamics 
of British stock exchange is not explained by the others stock indices. In addition, the fact that FTSE-100 is weakly exogenous implies that this index constitutes a common stochastic trend driving the system. Thus, FTSE-100 might be capturing the effects on the EMU member stock indices coming from shocks originating outside the eurozone. As the other indices in the system are not weakly exogenous, they are adjusting to the cointegration relations. The degree of adjustment is captured by the loadings on the cointegration vectors. According to empirical results, the CAC-40 index adjusts to both cointegration relationships. The DAX and IBEX-35 adjust to the second whereas the MIBTEL adjusts to the first. Including the dummy variable significantly affects the dynamics for the CAC-40, DAX and IBEX-35 indices, therefore highlighting the importance of the introduction of the euro to our understanding of the degree of market comovoments in the EMU zone.

Next we discuss to what extend these cointegration results can be interpreted in terms of financial market integration. A significant number of papers have examined the international integration of equity markets by using cointegration techniques. These papers are based on the premise that if two markets are economically integrated and their respective prices are $\mathrm{I}(1)$, then these prices must be cointegrated. Thus, Bernard (1992), pointed out that a necessary condition for complete integration is that there must be $n-1$ cointegration vectors in a system of $n$ stock prices. Taking into account that in our case, the FTSE-100 is weakly exogenous, complete integration would imply $r=3$. Our finding that $r=2$ implies therefore uncomplete integration. However, the recent paper of Lence and Falk (2005) demonstrate that the concept of integration is not necessarily related to either market integration or market efficiency. These authors consider a standard dynamic equilibrium asset pricing model to conclude that, in the absence of a sufficiently well-specified model, the tests of cointegration among asset prices have no implications about market integration without additional restrictions on the economy. Although, it should be highlighted that these authors consider the existence of market integration only when different countries display the same risk-adjusted expected returns.

\section{Modelling time-varying correlations}

The objective of the paper is to analyze the dynamic evolution of financial stock market integration. Following recent papers of Chelley-Steeley (2005), Fujii (2005) and Kim et al., (2005), we use the conditional correlation between stock index markets as a proxy of dynamic financial integration. There is overwhelming empirical evidence to show not only that distributions of daily stock index market returns are skewed with thick tails, but also that GARCH models are a suitable econometric tool for modelling conditional variances of stock index returns and their respective conditional covariances. Following the Engle's 
(1982) pathbreaking idea, numerous parametric specifications have been proposed in the literature to distinguish between conditional and unconditional second order moments. This case, we use the dynamic conditional correlation model proposed in Engle $(2002)^{3}$, which, to the best of our knolowgede, has not yet been used in the literature on the analysis of financial stock market integration. This specification is a generalization of the constant conditional correlation multivariate GARCH proposed in Bollerslev (1990), but has the flexibility of univariate GARCH models coupled with parsimonious parametric models for the correlations. To represent the dynamics of the conditional means of the stock market returns for each pair of countries considered, we posit the following error correction model:

$$
\begin{aligned}
& r_{i, t}=\alpha_{1 i} e c m 1_{t-1}+\alpha_{2 i} e c m 2_{t-1}+\gamma_{i} r_{i, t-1}+\delta_{i} r_{j, t-1}+\varepsilon_{i, t} \\
& r_{j, t}=\alpha_{1 j} e c m 1_{t-1}+\alpha_{2 j} e c m 2_{t-1}+\gamma_{j} r_{i, t-1}+\delta_{j} r_{j, t-1}+\varepsilon_{j, t} \\
& \varepsilon_{t}^{\prime}=\left(\varepsilon_{i, t}, \varepsilon_{j, t}\right) \sim N\left(0, H_{t}\right), \quad H_{t}=D_{t} R_{t} D_{t}, \quad D_{t}=\operatorname{diag}\left(\sqrt{h_{11, t}}, \sqrt{h_{22, t}}\right)
\end{aligned}
$$

that is, an $\mathrm{AR}(1)$ process with short-run adjustments that allows for spillover effects between the two countries, while the dynamics of the elements concerning the $H_{t}$ matrix is as follows:

$$
\begin{gathered}
h_{i i, t}=\omega_{i i}+\sum_{r=1}^{q} \alpha_{i r} \varepsilon_{i, t-r}^{2}+\sum_{k=1}^{p} \beta_{i k} h_{i i, t-k} \\
R_{t}=\left(Q_{t}^{*}\right)^{-1} Q_{t}\left(Q_{t}^{*}\right)^{-1}, Q_{t}=\operatorname{diag}\left(\sqrt{q_{11, t}}, \sqrt{q_{22, t}}\right) \\
Q_{t}=[1-\alpha(1)-\beta(1)] \bar{Q}+\sum_{i=1}^{q^{*}} \alpha_{i} L^{i} \eta_{t-1} \eta_{t-1}^{\prime}+\sum_{j=1}^{p^{*}} \beta_{j} L^{j} Q_{t-1}
\end{gathered}
$$

where $\eta_{t}^{\prime}=\varepsilon_{t}^{\prime} D_{t}^{-1}$ represents the vector of standardized residuals of the two univariate GARCH models. Finally,

\footnotetext{
${ }^{3}$ As Engle pointed out, Monte Carlo experiment reveals not only that the bivariate version of the DDC-MV-GARCH model provides a very good approximation to a variety of time-varying correlation processes, but also that the comparison of this model with simple multivariate GARCH shows that this model is often the most accurate.
} 


$$
\bar{Q}=T^{-1} \sum_{t=1}^{T} \varepsilon_{t} \varepsilon_{t}^{\prime}
$$

is the matrix of standardized inconditional covariances, where $T$ denotes the sample size.

The model is fitted via maximum likelihood estimation. The log likelihood function for this estimator can be expressed as ${ }^{4}$ :

$$
\begin{aligned}
L & =-\frac{1}{2} \sum_{t=1}^{T}\left(n \log (2 \pi)+\log \left|H_{t}\right|+r_{t}^{\prime} H_{t}^{-1} r_{t}\right)= \\
& =-\frac{1}{2} \sum_{t=1}^{T}\left(n \log (2 \pi)+2 \log \left|D_{t}\right|+r_{t}^{\prime} D_{t}^{-1} D_{t}^{-1} r_{t}-\varepsilon_{t} \varepsilon_{t}^{\prime}+\log \left|R_{t}\right|+\varepsilon_{t}^{\prime} R_{t}^{-1} \varepsilon_{t}\right)
\end{aligned}
$$

As stated above, the dynamic conditional correlations are estimated from bivariate DCC-MV-GARCH models, so our five-dimensional VEC model must consequently be reduced. Dimensional reduction presents two drawbacks, first, we impose zero restrictions to the short-run adjustment coefficients in the VECM (i.e., the lagged differences) for the variables not involved in the bivariate GARCH model; second, if cointegration is not robust to GARCH effects, the loadings to the cointegration vectors ( $\alpha$ coefficients) might present different values among the bivariate GARCH models and might also differ from those estimated in the five dimensional VECM. The models are estimated using the Broyden, Fletcher, Goldfarb and Shanno (BFGS) algorithm and the more parsimonious model that leads to uncorrelated standardized and squared standardized residuals was finally chosen

\section{$5 \quad$ Empirical results}

The bivariate error correction DCC-MV-GARCH model was found to be a valid parameterization of conditional first and second order moments of stock index returns. For all pairs of stock index returns considered, the LjungBox Q-statistic, reported in Table 5, does not systematically reject the null

\footnotetext{
${ }^{4}$ While several other conditional densities might be a preferable alternative in theory, like the generalized error distribution proposed in Nelson (1991), all useful specifications must necessarily restrict the dimensionality of the parameter space to be tractable. For this reason, and taking into account that conditional normality is able to capture many stylzed facts for stock returns reasonably well (see Franses and van Dijk, 2000, chp.4), we use the conditional Gaussian distribution.
} 
hypothesis of absence of autocorelation at the $1 \%$ significance level in both the standardized and squared standardized residuals.

Figures 2 to 4 depict the estimated conditional correlations from these bivariate error correction DCC-MV-models. In all cases, a significant change in the dynamics of integration between each pair of countries, including the UK, can be observed from 1996-1997 onwards. A clear trend in the conditional correlations takes place, revealing that financial integration significantly increases over time. Table 6 reports the average conditional correlation corresponding to the partitioned samples, taking into account the introduction of the euro. Although the financial integration increased between all pairs of countries considered, the lowest rise is seen in the financial integration with the UK, the country that behaves exogenously in the cointegration structure. Within the monetary union, the highest increase corresponds to Italy.

Interestingly enough, the volatility of time-varying correlations clearly diminishes once the common currency is in place. This pattern is similar to those reported by Kim et. al. (2005) between the same EMU countries and the eurozone. To statistically asses the increase of financial integration we compute the Kolmogorov-Smirnov test for the null hypothesis of both (pre-euro and after the euro) correlation distributions have the same cumulative probability distribution. The advantage of this test is that it makes no assumption about the distribution of data. Empirical results are reported in Table 7. In all cases the null hypothesis is systematically rejected, suggesting that the introduction of the euro has led to a regime shift in the process of financial integration. Table 7 also reports the confidence interval for the conditional correlation after January 1, $1999^{5}$ using the Tchebycheff inequality. The interval is carried out with at a maximum of $10 \%$ significance level. On comparing information in Table 6 and Table 7, we reject the hypothesis of equal average correlation. Only for two cases (Germany-UK and Spain-UK) does the confidence interval contain the average value corresponding to the pre-euro subsample. However this average value falls on the border of the confidence interval, so the acceptance of equal average correlation before and after the introduction of the euro is not statistically clear.

Concerning the error correction mechanism, in our estimated five-dimensional VECM, only five out of 48 short-run adjustment coefficients are statistically significant; this we impose at most one zero restriction on the conditional mean of the bivariate GARCH models. In our case, the imposition of zero restrictions does not seem to be a major concern. Table 4 presents the loadings on the cointegration relationships for the ten bivariate GARCH models (one model for each pair of variables involved in the VECM). The estimates were

\footnotetext{
${ }^{5}$ The use of standard deviation is more appropriate as a measure of variability for time varying conditional correlation after the introduction of the euro because in this subsample the dynamic of correlations is mean stationary
} 
obtained by taking the cointegration vectors as fixed during the estimation of the GARCH model. Direct estimation of the cointegration vectors directly by maximum likelihood is not very successful since modest changes to the cointegrating vector force rather large changes to other components. As can be seen in Table 4, France, Germany and Spain are error correcting to the second cointegration relationship, whereas Italy corrects to the first one. The United Kingdom is weakly exogenous. These results are robust for all the ten bivariate GARCH models ${ }^{6}$ and replicate the results obtained for the five dimensional VECM.

The above results suggest that the introduction of the euro is a factor that encourages financial integration, rather than its original cause. To reinforce the previous argument, next we analyze the principal component structure of the estimated time varying correlations. If the introduction of the euro has led to a strengthening of financial integration, a powerful linear dimensionality reduction of the correlation data set may have been achieved with the principal component technique. However the nature of the principal component structure should be similar if financial integration triggered after common currency introduction.

\subsection{Principal components structure of conditional corre- lations}

The objective of principal component analysis is to obtain a few uncorrelated variables (principal components) in terms of linear combinations of original variables so as to maximize the variance of these components. This objective becomes especially interesting in multivariate analysis when using a large number of interrelated variables. In our case, a reduction in dimensionality may be useful to provide additional insights into financial integration. In this section we analyze the principal component structure of the estimated conditional correlations. If financial integration has strengthened after the introduction of the euro, either the same number of components factors should explain a greater percentage of the variance, or a lower number of factors should explain at least the same percentage of the variance.

The model can be stated as follows:

$\rho=L f+D u$

where $\rho$ is a $10 \times 1$ vector of standardized conditional correlations, $L$ is a $10 \times r(<10)$ matrix of loadings (weights of each variable in components), $f^{\prime}=\left(f_{1}, f_{2}, \ldots, f_{m}\right)$ is the matrix corresponding to the principal components and $D$ is a diagonal matrix of loadings corresponding to the specific factors $u^{\prime}=\left(u_{1}, u_{2}, \ldots, u_{m}\right)$. Let us denote the covariance matrix of correlations as $S$.

\footnotetext{
${ }^{6}$ The only exception is Spain in model 6, which also corrects to the first cointegration relationship.
} 
This matrix can be transformed into a diagonal matrix using the orthonormal transformation, that is:

$$
\Lambda=\Gamma^{\prime} L L^{\prime} \Gamma+\Gamma^{\prime} E \Gamma
$$

where $\Gamma$ is the orthonormal matrix whose columns are the eigenvectors of matrix $S, E=D^{\prime} D$ is the residual matrix and $\operatorname{tr}(\Lambda)=\operatorname{tr}(S)$. In this way, for a given number of $p$ components, the matrix of loadings can be estimated through the $p$ eigenvectors which correspond to the $p$ largest eigenvalues of matrix $S$ using the following expression:

\section{$\hat{L}=\Gamma \Lambda^{\frac{1}{2}}$}

Table 8 reports the principal component structure for the estimated conditional correlations from the full sample, and from the two subsamples corresponding before and after January 1, 1999. The qualitative nature of the solution is similar in the full sample and after the introduction of the euro; in both cases, using the average root as the stopping rule (eigenvalues greater than one), only one component arises. However, in the pre-euro sample one additional factor appears to be considered. Interestingly, the first factor has greater explanatory ability in the post-euro sample, revealing that it is more representative of the time evolution of conditional correlations after the introduction of the euro. These aspects corroborate our finding that although financial integration took place before monetary union, financial integration became stronger after the introduction of the common currency.

\section{Summary and Conclusions}

This paper investigates the dynamic nature of financial integration for the main eurozone member countries (Germany, France, Spain and Italy) and the UK. The innovation of the paper lies in taking into account the long run stock market dynamics to investigate the financial integration in the short-run. Using time varying correlation as a proxy of the degree of dynamic financial integration, a bivariate error correction DCC-MV-GARCH model is used to estimate conditional correlations between stock index returns during the sample period 1993-2004. Our empirical findings show the existence of two long-run equilibrium relationships between stock market indices, but these indices are cointegrated once we allow a structural change in the long-run equilibrium relationship corresponding to the introduction of the euro. The existence of a long-run equilibrium across stock indices implies some degree of market predictability in the sense that deviations away from equilibrium are expected to be corrected in the short-run. This can be interpreted as a reduction of arbitrage opportunities between stock markets after the removal of exchange rate risk. Thus, the potential benefits of international diversification from European portfolios have declined.

According to the time evolution of the conditional correlations, in general, 
the introduction of the euro has increased the degree of financial integration among markets of the EMU countries. The highest increase corresponds to Italy. As expected, financial integration of the EMU countries with the UK has undergone a lower rise. In summary, our results suggest that a new age of financial integration was due to fiscal and monetary policies implemented in the European countries to achieve macroeconomic convergence conditions. The introduction of the EMU, rather than marking the origin of financial integration, appears to be a factor that consolidates this dynamic process.

\section{References}

Ayuso, J. and R. Blanco, 2001, Has financial market integration increased during the nineties?, Journal of International Financial Markets Institutions and Money 11, 265-287.

Berben, R.P. and W.J. Jansen, 2005, Comovement in international equity markets: A sectorial view, Journal of International Money and Finance 24, 832-857.

Bernard, A., 1992, Empirical implications of the convergence hypothesis, MIT Working Paper.

Bollerslev, T. (1990), Modelling the coherence in the short-run nominal exchange rates: A multivariate ARCH approach, Review of Economic and Statistics 72, 498-505.

Chelley-Steeley, P.L. (2005), Modelling equity market integration using smooth transition analysis: A study of Eastern European stock markets, Journal of International Money and Finance Finance 24, 818-831.

Engle, R. F. (1982), Autoregressive conditional heteroskedasticity with estimates of variance of U.K. inflation. Econometrica 50, 987-1008.

Engle, R. F. (2002), Dynamic conditional correlation: A simple class of multivariate generalized autoregressive conditional heteroskedasticity models, Journal of Business and Economic Statistics 20, 339-350.

Franses, P.H. and D. van Dijk (2000), Non-linear time series models in empirical finance, Cambridge Univeristy Press.

Fujii, E., 2005, Intra and inter-regional causal linkages of emerging stock markets: evidence from Asia and Latin America in and out of crisis, Journal of International Financial Markets Institutions and Money 15, 315-342.

Gonzalo, J, 1994, Five Alternative Methods of Estimating Long Run Equilibrium Relationships, Journal of Econometrics, 60, 1-31.

Hansen, H. and S. Johansen, 1999, Some Tests for Parameter Constancy in Cointegrated VAR-Models, Econometrics Journal, 2/2, 306-333.

Imbs, J., 2006, The real effects of financial integration, Journal of International Economics 68, 296-324. 
Johansen, S., 1988, Statistical Analysis of Cointegration Vectors, Journal of Economic Dynamics and Control, 12, 231-254

Jong de, Frank and F.A. de Roon, Time-varying market integration and expected returns in emerging markets, Journal of Financial Economics 78, 583-613.

Kim, S.J., Moshirian F. and E. Wu, 2006, Evolution of international stock and bond market integration: Influence of the European Monetary Union, Journal of Banking and Finance 30, 1507-1534.

Kim, S.J., Moshirian F. and E. Wu, 2005, Dynamic stock market integration driven by the European monetary union: An empirical analysis, Journal of Banking and Finance 29, 2475-2502.

Kose, M.A., Prasad E.S. and M.E. Terrones, 2006, How do trade and financial integration affect the relationship between growth and volatility?, Journal of International Economics 69, 176-202.

Lence, S. and B. Falk, 2005, Cointegration, market integration and market efficiency, Journal of International Money and Finance 24, 873-890.

Nelson, D.B, 1991, Conditional heteroskedasticity in asset returns: A new approach, Econometrica 59, 318-334.

Portes, R. and H. Rey, 2005, The determinants of cross border equity flows, Journal of International Economics 65, 269-296. 
Table 1: Descriptive statistics

\begin{tabular}{lccccc}
\hline \hline & & & & & \\
& France & Germany & Spain & Italy & UK \\
Mean(in percentage) & 0.0328 & 0.0448 & 0.0503 & 0.0506 & 0.0325 \\
Standard Deviation & 1.5134 & 1.6703 & 1.5833 & 1.6984 & 1.2081 \\
Skewness & 0.0266 & -0.0071 & 0.2499 & 0.2235 & -0.1158 \\
Excess of Kurtosis & 1.8811 & 1.9863 & 4.5277 & 4.3647 & 2.0299 \\
& & & & & \\
& & & & & \\
ARCH(5) & 44.8184 & 59.3966 & 14.1212 & 43.6717 & 62.3152 \\
& {$[0.00]$} & {$[0.00]$} & {$[0.00]$} & {$[0.00]$} & {$[0.00]$} \\
\hline \hline
\end{tabular}

ARCH(5) denotes Engle's Lagrange Multiplier test for ARCH effects considering five lags. P-values are in brackets. 
Table 2: The cointegration rank

Modulus of the 6 largest characteristic roots

$\begin{array}{lllllll}r=3 & 1.00 & 1.00 & 1.00 & 1.00 & 0.98 & 0.21 \\ r=2 & 1.00 & 1.00 & 1.00 & 0.98 & 0.97 & 0.22 \\ r=1 & 1.00 & 1.00 & 0.99 & 0.98 & 0.97 & 0.22\end{array}$

Adjustment coeficientes (t-ratios)

$\begin{array}{lccccc} & \text { CAC-40 } & \text { DAX } & \text { IBEX-35 } & \text { MIBTEL } & \text { FTSE-100 } \\ \hat{\alpha}_{1} & \mathbf{- 2 . 0 9} & \mathbf{3 . 4 7} & \mathbf{3 . 1 8} & \mathbf{4 . 7 1} & \mathbf{2 . 4 1} \\ \hat{\alpha}_{2} & \mathbf{- 2 . 2 2} & \mathbf{- 2 . 4 6} & \mathbf{- 2 . 7 6} & -0.12 & 0.37 \\ \hat{\alpha}_{3} & -0.83 & -2.03 & -0.31 & 0.58 & \mathbf{- 2 . 3 8}\end{array}$

Trace test

\begin{tabular}{cccccc}
$p-r$ & $r$ & Trace & Trace* & Cval95 & Cval95* $^{*}$ \\
5 & 0 & 90.25 & 89.63 & 76.81 & 89.07 \\
4 & 1 & 60.14 & 58.30 & 53.94 & 61.84 \\
3 & 2 & 34.24 & 32.97 & 35.07 & 43.52 \\
2 & 3 & 18.36 & 16.97 & 20.16 & 26.38 \\
1 & 4 & 6.80 & 5.68 & 9.14 & 13.00 \\
\hline \hline
\end{tabular}

Probability in brackets. Bold face indicates $\mid t-$ ratio $\mid>2$. Trace* stands for the Barlett corrections to the standard Trace test for the I1-model. Cval95 is the critical values corresponding to a model without dummies. Cval95* is the simulated critical values at $5 \%$ for the I1-model with shift dummies. 
Table 3: Time series properties in the VAR

\begin{tabular}{|c|c|c|c|c|c|c|c|}
\hline \multicolumn{8}{|c|}{ Test for variable exclusion } \\
\hline $\mathrm{r}$ & $\operatorname{dgf}$ & $\chi^{2}(r)$ & $\mathrm{CAC}$ & DAX & IBEX-35 & MIBTEL & FTSE-100 \\
\hline 1 & 1 & 3.84 & $\begin{array}{c}0.27 \\
{[0.59]}\end{array}$ & $\begin{array}{c}3.14 \\
{[0.08]}\end{array}$ & $\begin{array}{c}0.06 \\
{[0.78]}\end{array}$ & $\begin{array}{c}1.49 \\
{[0.22]}\end{array}$ & $\begin{array}{c}1.39 \\
{[0.24]}\end{array}$ \\
\hline 2 & 2 & 5.99 & $\begin{array}{l}7.13 \\
{[0.02]}\end{array}$ & $\begin{array}{l}8.16 \\
{[0.01]}\end{array}$ & $\begin{array}{l}9.83 \\
{[0.00]}\end{array}$ & $\begin{array}{l}8.12 \\
{[0.01]}\end{array}$ & $\begin{array}{l}11.32 \\
{[0.00]}\end{array}$ \\
\hline 3 & 3 & 7.81 & $\begin{array}{l}7.36 \\
{[0.06]}\end{array}$ & $\begin{array}{l}11.19 \\
{[0.01]}\end{array}$ & $\begin{array}{l}11.70 \\
{[0.00]}\end{array}$ & $\begin{array}{l}13.34 \\
{[0.00]}\end{array}$ & $\begin{array}{l}16.57 \\
{[0.00]}\end{array}$ \\
\hline \multicolumn{8}{|c|}{ Test for stationarity } \\
\hline $\mathrm{r}$ & $\operatorname{dgf}$ & $\chi^{2}(r)$ & $\mathrm{CAC}$ & DAX & IBEX-35 & MIBTEL & FTSE-100 \\
\hline 1 & 4 & 9.48 & $\begin{array}{l}20.58 \\
{[0.00]}\end{array}$ & $\begin{array}{l}18.40 \\
{[0.00]}\end{array}$ & $\begin{array}{l}22.61 \\
{[0.00]}\end{array}$ & $\begin{array}{l}20.78 \\
{[0.00]}\end{array}$ & $\begin{array}{l}20.43 \\
{[0.00]}\end{array}$ \\
\hline 2 & 3 & 7.81 & $\begin{array}{l}18.22 \\
{[0.00]}\end{array}$ & $\begin{array}{l}16.24 \\
{[0.00]}\end{array}$ & $\begin{array}{l}19.98 \\
{[0.00]}\end{array}$ & $\begin{array}{l}18.76 \\
{[0.00]}\end{array}$ & $\begin{array}{l}17.50 \\
{[0.00]}\end{array}$ \\
\hline 3 & 2 & 5.99 & $\begin{array}{l}9.00 \\
{[0.01]}\end{array}$ & $\begin{array}{l}7.22 \\
{[0.02]} \\
\end{array}$ & $\begin{array}{l}10.40 \\
{[0.00]}\end{array}$ & $\begin{array}{l}10.74 \\
{[0.00]} \\
\end{array}$ & $\begin{array}{l}8.81 \\
{[0.01]} \\
\end{array}$ \\
\hline \multicolumn{8}{|c|}{ Test for weak exogeneity } \\
\hline $\mathrm{r}$ & $\operatorname{dgf}$ & $\chi^{2}(r)$ & $\mathrm{CAC}$ & DAX & IBEX-35 & MIBTEL & FTSE-100 \\
\hline 1 & 1 & 3.84 & $\begin{array}{c}2.61 \\
{[0.10]}\end{array}$ & $\begin{array}{c}3.16 \\
{[0.07]}\end{array}$ & $\begin{array}{c}3.13 \\
{[0.08]}\end{array}$ & $\begin{array}{c}2.78 \\
{[0.09]}\end{array}$ & $\begin{array}{c}0.38 \\
{[0.54]}\end{array}$ \\
\hline 2 & 2 & 5.99 & $\begin{array}{l}5.26 \\
{[0.07]}\end{array}$ & $\begin{array}{l}6.48 \\
{[0.03]}\end{array}$ & $\begin{array}{l}7.83 \\
{[0.01]}\end{array}$ & $\begin{array}{l}12.78 \\
{[0.00]}\end{array}$ & $\begin{array}{c}3.37 \\
{[0.18]}\end{array}$ \\
\hline 3 & 3 & 7.81 & $\begin{array}{l}7.12 \\
{[0.07]}\end{array}$ & $\begin{array}{l}11.63 \\
{[0.00]}\end{array}$ & $\begin{array}{l}10.49 \\
{[0.01]}\end{array}$ & $\begin{array}{l}14.47 \\
{[0.00]}\end{array}$ & $\begin{array}{c}6.48 \\
{[0.09]}\end{array}$ \\
\hline
\end{tabular}

In the test for stationarity, a restricted intercept is included in the cointegrating relation(s). Probability is shown in brackets. 
Table 4: Estimated error correction coefficients in the DCC-MV-GARCH

\begin{tabular}{|c|c|c|c|}
\hline \multirow{3}{*}{ Model 1} & \multirow{3}{*}{$\begin{array}{c}\text { Germany } \\
\text { France }\end{array}$} & $\alpha_{1}$ & $\alpha_{2}$ \\
\hline & & $\begin{array}{c}0.0010 \\
{[0.69]}\end{array}$ & $-\underset{[0.00]}{-0.0124}$ \\
\hline & & $\begin{array}{c}-0.0022 \\
{[0.46]}\end{array}$ & $\begin{array}{c}-\mathbf{0 . 0 1 1 1} \\
{[0.00]}\end{array}$ \\
\hline \multirow[t]{2}{*}{ Model 2} & Germany & $\begin{array}{c}0.0004 \\
{[0.93]}\end{array}$ & $-\mathbf{0 . 0 1 2 6}$ \\
\hline & Italy & $\begin{array}{c}\mathbf{0 . 0 1 2 8} \\
{[0.00]}\end{array}$ & $\begin{array}{c}-0.0027 \\
{[0.50]}\end{array}$ \\
\hline \multirow[t]{2}{*}{ Model 3} & Germany & $\begin{array}{c}0.0019 \\
{[0.70]}\end{array}$ & $-\underset{[0.04]}{\mathbf{0 . 0 0 8 5}}$ \\
\hline & Spain & $\begin{array}{c}-0.0011 \\
{[0.98]}\end{array}$ & $\begin{array}{c}-\mathbf{0 . 0 1 1 2} \\
{[0.01]}\end{array}$ \\
\hline \multirow[t]{2}{*}{ Model 4} & Germany & $\begin{array}{c}0.0009 \\
{[0.82]}\end{array}$ & $-\mathbf{0 . 0 1 1 3}$ \\
\hline & United Kingdom & $\begin{array}{c}0.0052 \\
{[0.08]}\end{array}$ & $\begin{array}{c}0.0021 \\
{[0.52]}\end{array}$ \\
\hline \multirow[t]{2}{*}{ Model 5} & France & $\begin{array}{c}-0.0071 \\
{[0.75]}\end{array}$ & $\underset{[0.00]}{-\mathbf{0 . 0 1 5 1}}$ \\
\hline & Italy & $\begin{array}{c}\mathbf{0 . 0 1 0 1} \\
{[0.03]}\end{array}$ & $\begin{array}{c}-0.0087 \\
{[0.51]} \\
\end{array}$ \\
\hline \multirow[t]{2}{*}{ Model 6} & France & $\begin{array}{c}0.0005 \\
{[0.79]}\end{array}$ & $-\mathbf{- 0 . 0 1 1 3}_{[0.00]}$ \\
\hline & Spain & $\begin{array}{c}\mathbf{0 . 0 0 5 0} \\
{[0.00]}\end{array}$ & $\begin{array}{c}-\mathbf{0 . 0 1 2 6} \\
{[0.00]}\end{array}$ \\
\hline \multirow[t]{2}{*}{ Model 7} & France & $\begin{array}{c}0.0003 \\
{[0.94]}\end{array}$ & $-\underset{[0.01]}{-0.0092}$ \\
\hline & United Kingdom & $\begin{array}{c}0.0059 \\
{[0.08]} \\
\end{array}$ & $\begin{array}{c}0.0021 \\
{[0.52]} \\
\end{array}$ \\
\hline \multirow[t]{2}{*}{ Model 8} & Italy & $\begin{array}{c}\mathbf{0 . 0 1 5 3} \\
{[0.00]}\end{array}$ & $\begin{array}{c}-0.0063 \\
{[0.17]}\end{array}$ \\
\hline & Spain & $\begin{array}{c}0.0142 \\
{[0.44]}\end{array}$ & $\begin{array}{c}-\mathbf{0 . 0 1 4 7} \\
{[0.00]}\end{array}$ \\
\hline \multirow[t]{2}{*}{ Model 9} & Italy & $\underset{[0.00]}{\mathbf{0 . 0 1 2 6}}$ & $\begin{array}{c}-0.0024 \\
{[0.59]}\end{array}$ \\
\hline & United Kingdom & $\begin{array}{c}0.0032 \\
{[0.23]}\end{array}$ & $\begin{array}{c}-0.0004 \\
{[0.90]}\end{array}$ \\
\hline \multirow[t]{2}{*}{ Model 10} & Spain & $\begin{array}{c}0.0046 \\
{[0.32]}\end{array}$ & $\underset{[0.03]}{-\mathbf{0 . 0 0 8 3}}$ \\
\hline & United Kingdom & $\begin{array}{c}0.0042 \\
{[0.22]}\end{array}$ & $\begin{array}{c}0.0025 \\
{[0.46]}\end{array}$ \\
\hline
\end{tabular}

Asymptotic p-values are shown in brackets, and significant coefficients in bold. $\alpha_{1}$ and $\alpha_{2}$ stand for the loadings to the first and second cointegration relationships, respectively. 
Table 5: Diagnosis test for the DCC-MV-GARCH model

\begin{tabular}{|c|c|c|c|}
\hline \multirow{3}{*}{ Model 1} & \multirow{3}{*}{$\begin{array}{c}\text { Germany } \\
\text { France }\end{array}$} & \multirow{3}{*}{$\begin{array}{c}\text { Standardized residuals } \\
\\
13.17 \\
{[0.87]} \\
29.73 \\
{[0.07]} \\
\end{array}$} & \multirow{3}{*}{$\begin{array}{l}\text { Squared standardized residuals } \\
\\
15.67 \\
{[0.61]} \\
17.65 \\
{[0.61]} \\
\end{array}$} \\
\hline & & & \\
\hline & & & \\
\hline \multirow[t]{2}{*}{ Model 2} & Germany & $\begin{array}{l}13.42 \\
{[0.86]}\end{array}$ & $\begin{array}{l}13.35 \\
{[0.50]}\end{array}$ \\
\hline & Italy & $\begin{array}{l}19.22 \\
{[0.51]} \\
\end{array}$ & $\begin{array}{l}29.23 \\
{[0.08]} \\
\end{array}$ \\
\hline \multirow[t]{2}{*}{ Model 3} & Germany & $\begin{array}{l}14.32 \\
{[0.81]}\end{array}$ & $\begin{array}{l}13.71 \\
{[0.84]}\end{array}$ \\
\hline & Spain & $\begin{array}{l}30.56 \\
{[0.06]} \\
\end{array}$ & $\begin{array}{c}7.58 \\
{[0.99]} \\
\end{array}$ \\
\hline \multirow[t]{2}{*}{ Model 4} & Germany & $\begin{array}{l}15.52 \\
{[0.75]}\end{array}$ & $\begin{array}{l}12.10 \\
{[0.91]}\end{array}$ \\
\hline & United Kingdom & $\begin{array}{l}20.45 \\
{[0.43]}\end{array}$ & $\begin{array}{l}13.55 \\
{[0.85]}\end{array}$ \\
\hline \multirow[t]{2}{*}{ Model 5} & France & $\begin{array}{l}31.40 \\
{[0.05]}\end{array}$ & $\begin{array}{l}17.05 \\
{[0.65]}\end{array}$ \\
\hline & Italy & $\begin{array}{l}17.36 \\
{[0.63]} \\
\end{array}$ & $\begin{array}{l}20.85 \\
{[0.40]} \\
\end{array}$ \\
\hline \multirow[t]{2}{*}{ Model 6} & France & $\begin{array}{l}28.73 \\
{[0.09]}\end{array}$ & $\begin{array}{l}18.75 \\
{[0.54]}\end{array}$ \\
\hline & Spain & $\begin{array}{l}28.84 \\
{[0.09]} \\
\end{array}$ & $\begin{array}{l}10.56 \\
{[0.96]} \\
\end{array}$ \\
\hline \multirow[t]{2}{*}{ Model 7} & France & $\begin{array}{l}30.61 \\
{[0.06]}\end{array}$ & $\begin{array}{l}21.86 \\
{[0.35]}\end{array}$ \\
\hline & United Kingdom & $\begin{array}{l}22.99 \\
{[0.29]} \\
\end{array}$ & $\begin{array}{l}21.69 \\
{[0.36]} \\
\end{array}$ \\
\hline \multirow[t]{2}{*}{ Model 8} & Italy & $\begin{array}{l}21.19 \\
{[0.39]}\end{array}$ & $\begin{array}{l}22.49 \\
{[0.31]}\end{array}$ \\
\hline & Spain & $\begin{array}{l}28.55 \\
{[0.10]}\end{array}$ & $\begin{array}{l}8.53 \\
{[0.98]}\end{array}$ \\
\hline \multirow[t]{2}{*}{ Model 9} & Italy & $\begin{array}{l}17.85 \\
{[0.59]}\end{array}$ & $\begin{array}{l}33.60 \\
{[0.03]}\end{array}$ \\
\hline & United Kingdom & $\begin{array}{l}21.13 \\
{[0.39]}\end{array}$ & $\begin{array}{l}26.64 \\
{[0.15]} \\
\end{array}$ \\
\hline \multirow[t]{2}{*}{ Model 10} & Spain & $\begin{array}{l}31.60 \\
{[0.05]}\end{array}$ & $\begin{array}{l}13.77 \\
{[0.84]}\end{array}$ \\
\hline & United Kingdom & $\begin{array}{l}21.19 \\
{[0.38]}\end{array}$ & $\begin{array}{l}11.32 \\
{[0.94]}\end{array}$ \\
\hline
\end{tabular}

Empirical values of the Ljung-Box Q-statistics for the null hypothesis of absence of autocorrelation allowing for 20 lags. P-values are shown in brackets 
Table 6: Average estimated conditional correlations

\begin{tabular}{|c|c|c|c|}
\hline & pre-EMU & post-EMU & Variation Rate \\
\hline \multicolumn{4}{|l|}{ Correlations } \\
\hline Germany-France & 0.57 & 0.85 & $47.68 \%$ \\
\hline Germany-Italy & 0.34 & 0.79 & $133.96 \%$ \\
\hline Germany-Spain & 0.53 & 0.76 & $43.78 \%$ \\
\hline Germany-United Kingdom & 0.53 & 0.69 & $30.89 \%$ \\
\hline France-Italy & 0.47 & 0.86 & $82.25 \%$ \\
\hline France-Spain & 0.63 & 0.83 & $32.63 \%$ \\
\hline France-United Kingdom & 0.60 & 0.75 & $24.61 \%$ \\
\hline Italy-Spain & 0.47 & 0.81 & $74.54 \%$ \\
\hline Italy-United Kingdom & 0.38 & 0.70 & $84.26 \%$ \\
\hline Spain-United Kingdom & 0.54 & 0.66 & $22.82 \%$ \\
\hline
\end{tabular}


Table 7: Non-parametric testing from estimated conditional correlations

\begin{tabular}{|c|c|c|}
\hline & KS test & Confidence Interval \\
\hline Germany-France & $\begin{array}{c}0.82 \\
{[0.00]}\end{array}$ & {$[0.66,1.00]$} \\
\hline Germany-Italy & $\begin{array}{l}0.88 \\
{[0.00]}\end{array}$ & {$[0.60,1.00$} \\
\hline Germany-Spain & $\begin{array}{c}0.77 \\
{[0.00]}\end{array}$ & {$[0.56,1.00]$} \\
\hline Germany-United Kingdom & $\begin{array}{c}0.65 \\
{[0.00]}\end{array}$ & {$[0.52,1.00]$} \\
\hline France-Italy & {$[0.84$} & {$[0.74,1.00]$} \\
\hline France-Spain & {$[0.72$} & {$[0.73,1.00]$} \\
\hline France-United Kingdom & $\begin{array}{l}0.48 \\
{[0.00]}\end{array}$ & {$[0.61,1.00]$} \\
\hline Italy-Spain & $\begin{array}{c}0.68 \\
{[0.00]}\end{array}$ & {$[0.66,1.00]$} \\
\hline Italy-United Kingdom & $\begin{array}{c}0.73 \\
{[0.00]}\end{array}$ & {$[0.47,1.00]$} \\
\hline Spain-United Kingdom & $\begin{array}{c}0.49 \\
{[0.00]}\end{array}$ & {$[0.48,0.98]$} \\
\hline
\end{tabular}

The KS column reports the Kolmogorov-Smirnov test for the null hypothesis that both correlations distributions are identical. The eigenvalues greater than one of each component in the pre-euro period are 6.60 and 1.16, while for the unique component in the post-euro period and the full sample are 7.37 and 8.13 , respectively. The confidence interval, which is carried out using the Tchebycheff inequality with at least $90 \%$ confidence level, corresponds to the correlation after the introduction of the euro. 
Table 8: Principal component structure of conditional correlations

\begin{tabular}{|c|c|c|c|c|}
\hline \multirow[b]{2}{*}{ Correlations } & \multicolumn{2}{|c|}{ pre-EMU } & \multirow{2}{*}{$\begin{array}{l}\text { post-EMU } \\
\text { Component } 1\end{array}$} & \multirow{2}{*}{$\begin{array}{l}\text { Full sample } \\
\text { Component } 1\end{array}$} \\
\hline & Component 1 & Component 2 & & \\
\hline Germany-France & 0.851 & 0.242 & 0.764 & 0.924 \\
\hline Germany-Italy & 0.904 & -0.154 & 0.865 & 0.945 \\
\hline Germany-Spain & 0.817 & 0.205 & 0.870 & 0.923 \\
\hline Germany-United Kingdom & 0.721 & 0.534 & 0.880 & 0.872 \\
\hline France-Italy & 0.809 & -0.444 & 0.880 & 0.920 \\
\hline France-Spain & 0.807 & -0.223 & 0.935 & 0.928 \\
\hline France-United Kingdom & 0.791 & 0.385 & 0.862 & 0.849 \\
\hline Italy-Spain & 0.751 & -0.560 & 0.707 & 0.854 \\
\hline Italy-United Kingdom & 0.884 & -0.110 & 0.906 & 0.952 \\
\hline Spain-United Kingdom & 0.908 & 0.163 & 0.891 & 0.835 \\
\hline Percentage of explained variance & $66.6 \%$ & $11.6 \%$ & $73.7 \%$ & $81.3 \%$ \\
\hline
\end{tabular}

The eigenvalues greater than one of each component in the pre-euro period are 6.60 and 1.16, while for the unique component in the post-euro period and the full sample are 7.37 and 8.13 , respectively 
Figure 1: Cointegration vectors
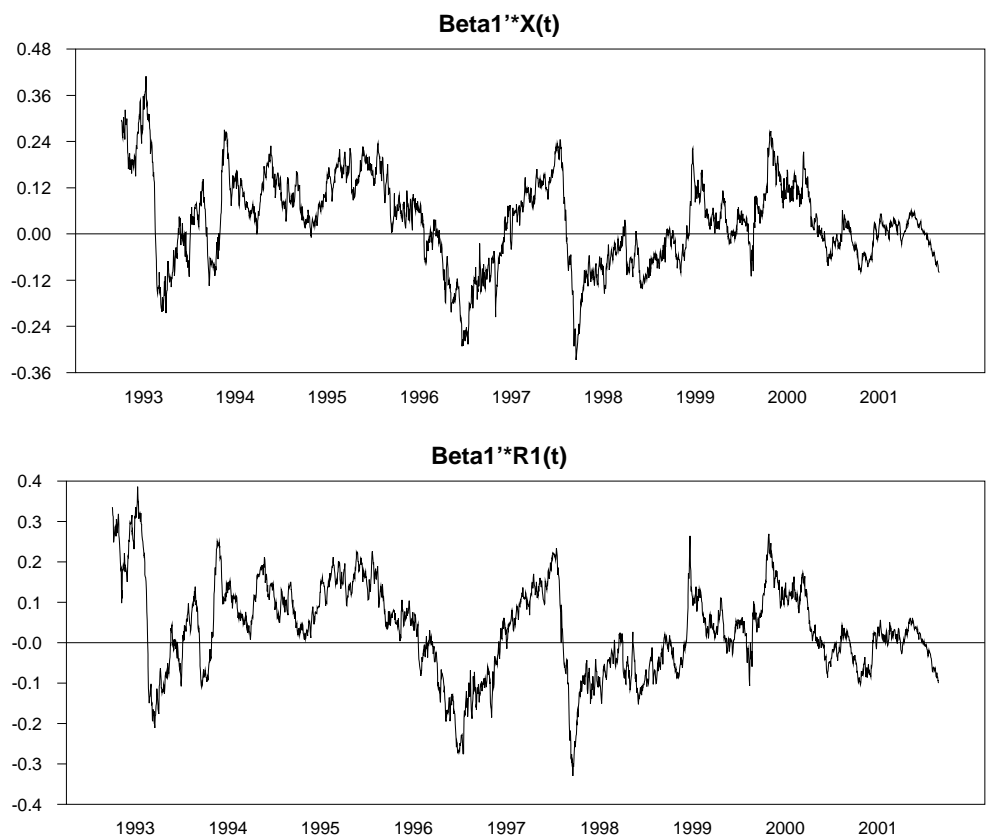

(a) First vector
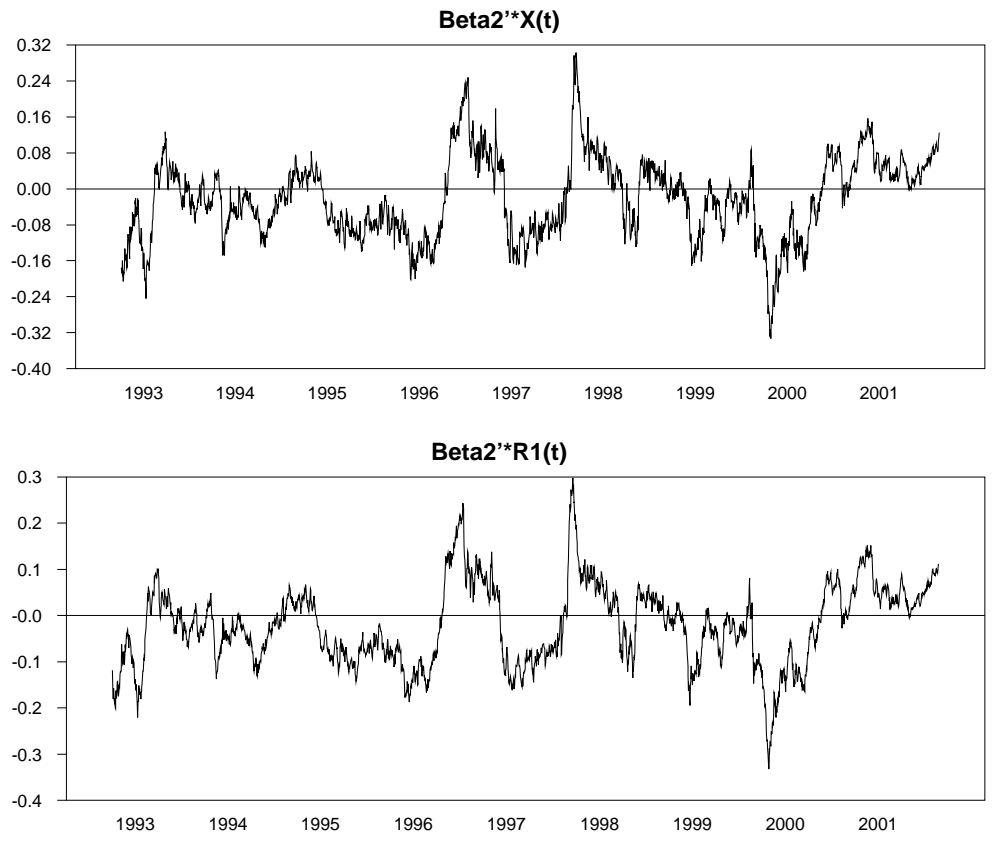

(b) Second vector 

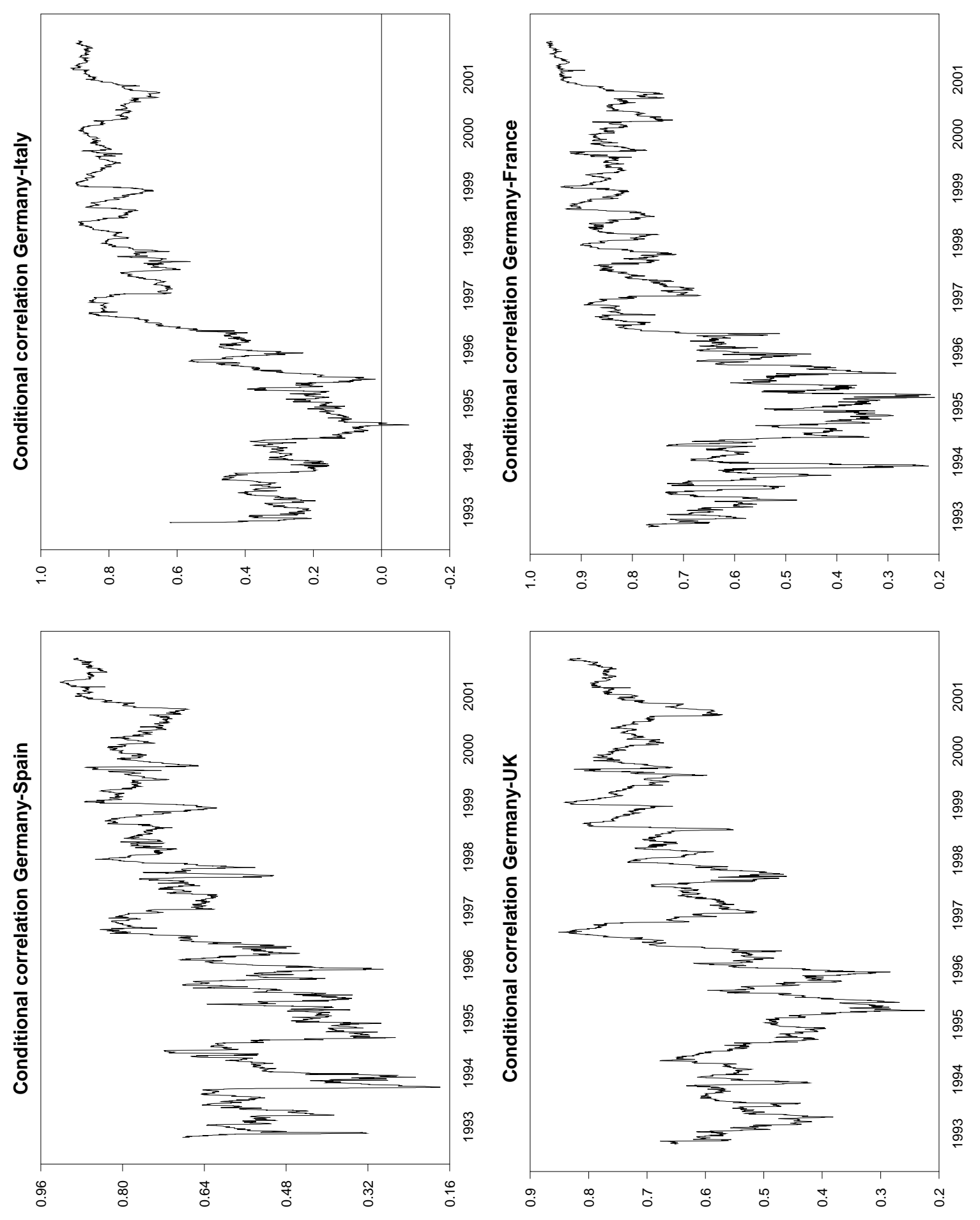

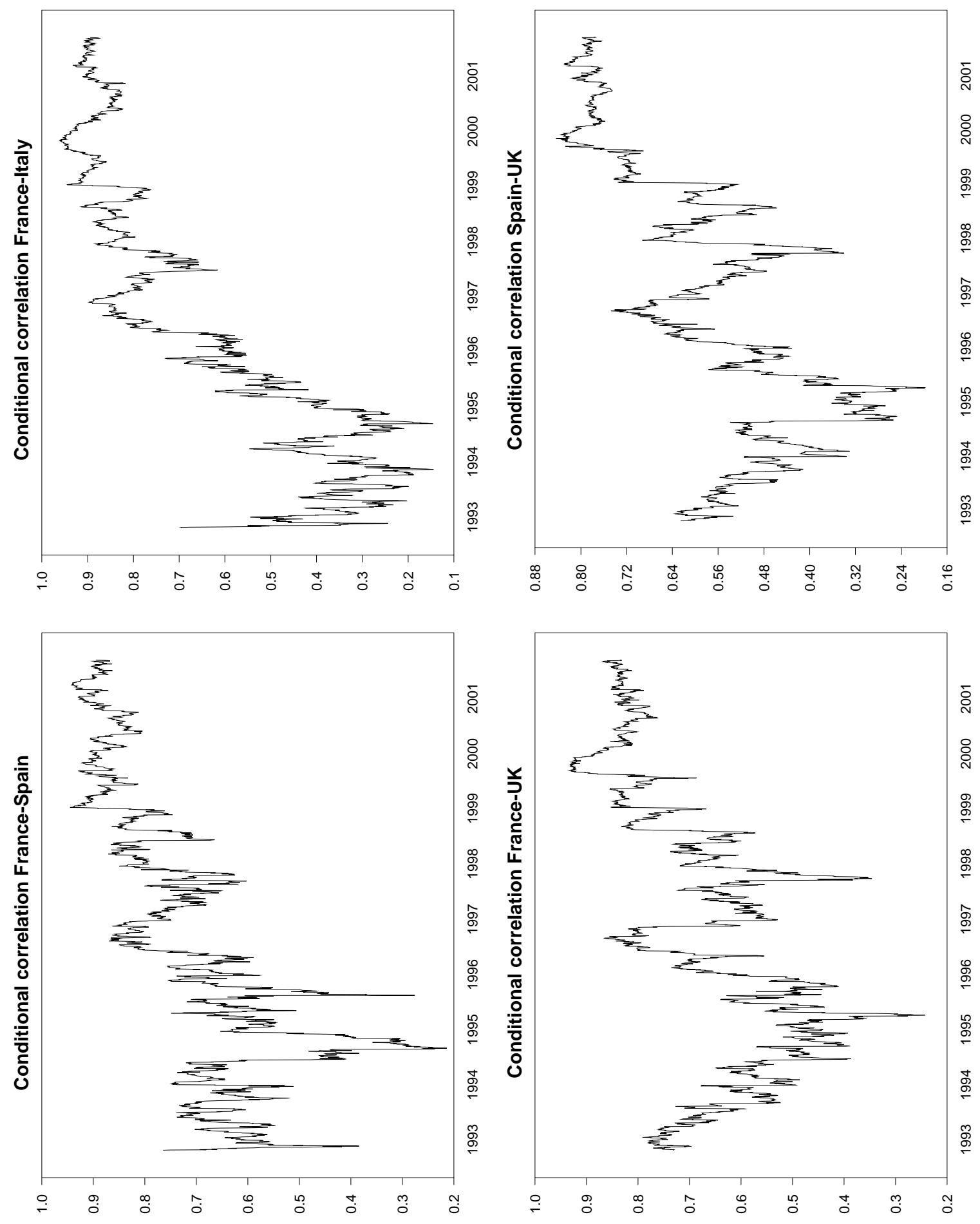

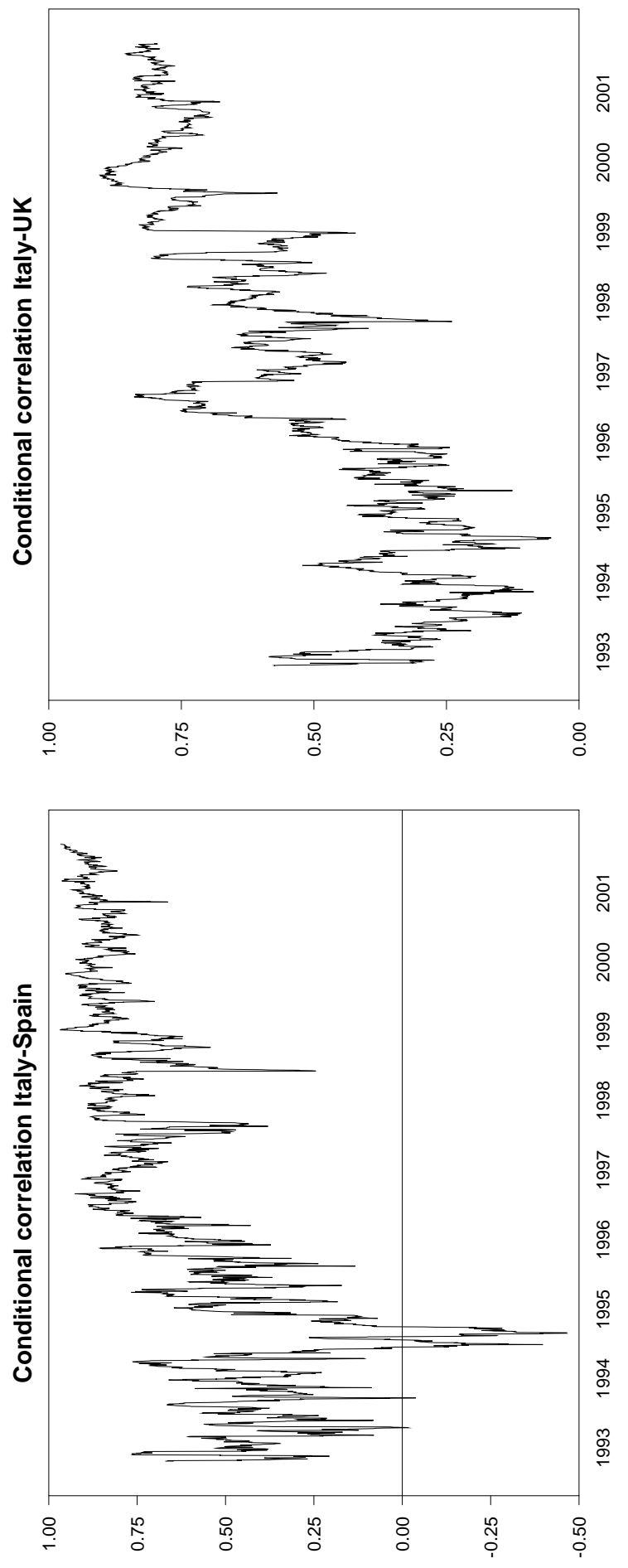